\title{
A Comparative Analysis of Attitudes Toward Immigrants
}

\author{
Ugur Orak ${ }^{1,2, *}$ and Ozgur Solakoglu ${ }^{3}$
}

${ }^{1}$ Louisiana State University, Baton Rouge, LA, USA

${ }^{2}$ Turkish Military Academy, Ankara, Turkey

${ }^{3}$ Sociology at Turkish Military Academy, Ankara, Turkey

\begin{abstract}
The current study examined attitudes toward immigrants in four countries including the United States, China, South Africa, and Turkey, differing from each other by their economic development levels and past immigration experiences. Although considerable attention has been paid to public attitudes toward immigrants, extant research have remained limited to economic and cultural factors as potential determinants of public attitudes, and they have failed to widen the scope of the issue. Thus, they have ignored the role of countries' past immigration practices and effective immigration policies in shaping natives' perceptions of immigrants. The current study has added some unique and valuable findings to the literature on attitudes toward immigrants by revealing the distinctive impacts of countries' past immigration experiences and their immigration policies on natives' perceptions of immigrants. By using data drawn from the 2015 Global @dvisor Survey, the current study also provided up-to-date research outcomes on the topic.
\end{abstract}

Keywords: Public attitudes, immigrants, policies, past experiences.

\section{INTRODUCTION}

Recently, immigrant population in many developing and developed countries have grown rapidly. The population of foreign-born people in the U.S., for example, is about two times more than it was in 1950; and for other countries such as Canada, United Kingdom, and Italy, the growth is even larger than the U.S. (Hainmueller and Hopkins 2014). Likewise, statistics collected by International Organization for Migration (IOM 2015) showed that, in global context, 64 million more people were living outside of their countries in 2010 compared to those in the year of 2000. Findings of these research demonstrate that the population of immigrants in the international context is growing exponentially. This substantial increase in immigrant population is followed by the concerns regarding public attitudes toward immigrants in host countries. Although a considerable amount of research has focused on attitudes toward immigrants in recent years, they have failed to provide consistent results (Esses, Brochu, and Dickson 2012; Hainmueller and Hopkins 2014; Ward and Masgoret 2008). At this point, the current study firstly intends to reveal the impacts of possible determinants of individuals' attitudes toward immigrants depending on their socioeconomic and personal characteristics. By doing this, it aims at providing empirical evidence-based grounds for the development of policy measures to integrate ethnically diverse societies.

*Address correspondence to this author at the Louisiana State University, Baton Rouge, LA, USA; Tel: 1-225-328-2761;

E-mail: ugurorak06@gmail.com
Numerous research in the pertinent literature highlighted that economic factors were primary drivers of public attitudes toward immigrants (Esses et al. 2012; Facchini and Mayda 2009; Paas and Halapuu 2012). Individual economic approach, for instance, suggested that natives developed negative attitudes toward immigrants when they felt a competition with immigrants in labor market (Paas and Halapuu 2012). Collective economic approaches, on the other hand, focused on countries' GDPs and growth rates as primary determinants of public attitudes toward immigrants. Both theoretical approaches, however, have ignored the potential impacts of countries' historical immigration experiences and effectiveness of their immigration policies in shaping their societies' attitudes toward immigrants. Thus, the current study secondly intends to reveal whether the effects of economic concerns on public attitudes toward immigrants are contingent upon countries' past immigration experiences and immigration policies. To achieve this objective, this study compares four countries including United States of America, China, South Africa, and Turkey. The reason behind selecting these countries for the comparison is that each countries have different economic development levels and distinctive immigration experiences. The United States and China, for example, are two biggest economic powers in the world with their astronomical GDPs and growth rates (World Bank 2015). In respect to immigration experiences and policies, however, China is far behind the United States. While the United States declared its first regulation of immigrants in 1875 and gained so much experiences on immigration policies up to the present (Zolberg 2006), the first 
immigration laws in China were regulated in 1985 (Fan 2008). Likewise, South Africa and Turkey are both developing countries with moderate GDPs and growth rates. With regard to immigration experiences and effective policies, however, South Africa is more advanced than Turkey. While South Africa has experienced so much immigration flows since $19^{\text {th }}$ century and its first major immigration legislation was regulated by the Immigrants Regulation Act in 1913 (Cohen 1997), immigration regulations in Turkey is rather a recent application dating back barely to 1990s (Kirisci 2000). By comparing the determinants of attitudes toward immigrants in each countries, the current study aims at revealing the distinctive impacts of long-serving immigration policies on eliminating negative attitudes toward immigrants resulting from economic concerns.

Since the immigration is a dynamic process in which amounts and sociodemographic characteristics of immigrants can change rapidly, the research on immigration and attitudes toward immigrants needs to be updated frequently. Accordingly, the current study finally intends to provide up-to-date findings on attitudes toward immigrants. To realize this objective, the current study draws upon data from the Global @dvisor Wave 71 Survey (G@71), which was administered and coordinated by IPSOS Research Company, and conducted between June $19^{\text {th }}$ and July $3^{\text {rd }}$ in 2015.

\section{BACKGROUND}

Due to the rapid growth in immigrant populations, an extensive literature on public attitudes toward immigrants has been formed in recent years. Extant research have highlighted that when there is a threat against natives' economic, cultural, and social interests, they are expected to exhibit negative and prejudiced behaviors toward immigrants (Murray and Marx 2013). Consistent with this point of view, a close examination of relevant literature demonstrated that there have been two fundamental perspectives in researching the attitudes toward immigrants and immigration: one approaches the issue from the point of economic factors, while the other one features noneconomic factors such as personal, cultural, religious, and political. The current study focused on economically oriented perspectives to reveal whether the effects of economic factors on attitudes toward immigrants are contingent upon receiving-countries' levels of economic development and experiences on immigrant policies.
Theories that examine attitudes toward immigrants from an economic perspective could be divided into two groups as individual and collective economic theories (Paas and Halapuu 2012). Individual economic theories suggested that individuals who were uneducated, unskilled, and with lower financial resources were more likely to exhibit negative attitudes toward immigrants. This was found to be a result of the potential competition between natives and immigrants in obtaining scarce resources and being employed in labor market (Paas and Halapuu 2012). When immigrants are overrepresented in low-paid jobs, for example, low-skilled natives tend to have more negative attitudes toward immigrants. Skilled natives, however, are more likely to exhibit positive attitudes toward immigrants than low-skilled natives, regardless of skill levels of immigrants (Paas and Halapuu 2012). Collective economic theories, on the other hand, are more interested in unemployment rates and gross domestic product in country level. They suggested that as unemployment rates in a country became higher, attitudes toward immigrants would be more intolerant. Similarly, when countries' GDP were higher, attitudes toward immigrants would be more positive. In addition, countries' growth rates were also found to be positively associated with attitudes toward immigrants (Paas and Halapuu 2012). Both approaches-individual and collective-examining attitudes toward immigrants from an economic perspective have been supported by numerous studies in relevant literature (Diaz, Saenz, and Kwan 2011; Esses, et al. 2012; Facchini and Mayda 2009).

Recently, economic factors have come into the forefront as the most crucial components in shaping individuals' attitudes toward immigrants and immigration. Especially household income, employment status, and changes in the gross domestic product growth rates have been considered as primary factors in the extant research focusing on the effects of economic factors on public attitudes toward immigrants. In their study, for instance, which compared attitudes toward immigrants in eight European countries, Facchini and Mayda (2009) stated that natives' negative attitudes toward immigrants were primarily fueled by negative consequences of immigration on countries' income distributions. Skilled immigrants were considered as problem by low-income natives, while there was an opposite pattern for highincome natives. Reasons behind low-income natives' concerns about skillful immigrants were that immigrants were considered as potential causes for increasing 
competition, inducing downward pressure on natives' incomes, and situation of uncertainty. High-income natives, on the other hand, perceived skilled immigrants as net contributors to the welfare state (Facchini and Mayda 2009). This suggests that there is a negative association between natives' income levels and their attitudes toward immigrants.

Consistent with Facchini and Mayda's (2009) study, Esses et al. (2012) suggested that natives' perceptions of economic costs and benefits of immigration played a significant role in shaping their attitudes toward immigrants. When immigrants were considered by natives as potential rivals with regard to material resources, then they would be more likely to develop negative attitudes toward immigrants. Aside from their negative attitudes toward immigrants, moreover, they could also tend to criticize or reduce support for programs and policies implemented to provide assistance to immigrants (Esses et al. 2012). The underlying reason for their radically negative attitudes that do not even support humanitarian assistance for immigrants is their perceptions of immigrants as the competitors in sharing their pecuniary advantages. This reveals that one of the main determinants of attitudes toward immigrants is whether immigrants are considered as competing with natives for economic resources or not.

In a similar vein, along with the competition in income distribution, employment status was also found to affect natives' attitudes toward immigrants living in their countries. In their study-which examines attitudes toward Mexican immigrants in Arizona-Diaz, Saenz, and Kwan (2011) suggested that economic dynamics might cause anti-immigrant attitudes and, moreover, they could lead policymakers to implement contentious legislation. They found that attitudes toward immigrants became more negative as unemployment increased. In addition, they also posited that as yearly GDP growth rate decreased, positive attitudes toward immigrants also decreased (Diaz et al. 2011). Findings suggest that natives do not only perceive immigrants as competitors for their pecuniary advantages, but also consider them as their competitors in employment system and sometimes barriers to find a job. This leads them to develop negative attitudes toward immigrants.

In another study, on the other hand, Becchetti, Rossetti, and Castriota (2010) examined the issue from a different perspective. Supportive of the relevant literature, they stated that household income and unemployment were significantly associated with attitudes toward immigrants. They suggested, however, that employment also affected attitudes toward immigrants negatively as well as unemployment affected (Becchetti et al. 2010). This suggests that employed natives can see immigrants as threats to their employment status and economic welfare.

Research presented thus far demonstrated that attitudes toward immigrants were primarily shaped by economic components such as employment status, household income, and GDP growth rates. In contrast to this approach, some research pointed out that noneconomic factors such as culture, religion, politics, and personal characteristics were more influential than economic factors in determining the nature of public attitudes toward immigrants. Hainmueller and Hopkins (2014), for example, suggested that attitudes toward immigrants were determined by symbolic concerns about the nation and these concerns were generally cultural. In another study comparing New Zealanders with European and Canadian individuals, Ward and Masgoret (2008) stated that there was a significant relationship between cultural diversity and attitudes toward immigrants. They suggested that since Canada was a multicultural country more than New Zealand and it had also 35 years of experience on multicultural policies, Canadian people were found to be more tolerant of immigrants than New Zealanders. Along with the culture, political factors were also important indicators of attitudes toward immigrants. According to Pardos-Prado (2011), when economic vulnerability and competition on scarce resources is low, political preferences play the most crucial role in shaping public attitudes toward immigrants. This suggests that political factors can be influential on attitudes toward immigrants only when economic factors are eliminated. Hence, it shows that economic factors are still more important than political factors in shaping attitudes toward immigrants.

In relevant literature, age, gender, and education level-as personal characteristics-were also considered as influential factors on attitudes toward immigrants (Solakoglu and Gurbuz 2015). According to François and Magni-Berton (2013), women are more intolerant of immigrants than men due to two reasons. Firstly, since there are some gender imbalances among immigrants-that they are generally maledominant-this changes the rates of women in demographic structure and in turn leads women to have more negative opinions toward immigrants. Secondly, as was mentioned in this study earlier, there 
is a negative relationship between individual income and attitudes toward immigrants (Facchini and Mayda 2009). As women are internationally less likely to have high-income jobs, they are more intolerant of immigrants in their countries. Consistent with this finding, Hainmueller and Hiscox (2007) found that women were generally intolerant of immigrants from rich countries, but the opposite pattern was true for the poor countries. This suggests that women are intolerant of immigrants when they consider them as skillful and competitive in reaching material resources.

Another important personal characteristic in extant research was natives' educational levels. Since education was generally used as a proxy for individuals' skill level, it was widely examined in the literature. According to Hainmueller and Hiscox (2007), for example, individuals with higher levels of education are more likely to have positive opinions toward immigrants, regardless of their skills and countries of origin. Similarly, in their article comparing individuals in Russia and Estonia, Tiiu and Demidova (2014) found that highly educated individuals had more positive opinions toward immigrants compared to less educated individuals in Estonia. These findings suggest that once educational level increases, individuals do not consider immigrants as their competitors anymore, because they feel themselves more skillful and sufficiently competitive to cope with immigrants in labor market.

\section{CURRENT STUDY}

Recently, immigrant populations in many developing and developed countries have grown rapidly. In parallel, increasing international mobility of people has paved the way for a diversification in sociodemographic and ethnic compositions of countries. Integrating immigrants-migrating from different countries with diverse cultural and ethnic structure-into the rest of society, therefore, has gained importance. In fact, ethnic and socioeconomic diversity in a country prepares proper conditions for economic development of that country, only when sufficient and strong integration policies are implemented. If countries do not have remarkable integration policies, there will be social and political tensions among individuals instead of an economic development.

From this point of view, examining the attitudes toward immigrants is substantially important to develop favorable integration policies and in turn to provide an economic development. At this point, this study seeks answers for the question: "What are the determinants affecting individuals' attitudes toward immigrants in their countries?" Thus, one aim of the current study is to clarify the possible determinants of individuals' attitudes toward immigrants depending on their socioeconomic (household income, employment status etc.) and personal characteristics (age, gender, education etc.). By doing this, the current study intends to provide empirical evidence-based grounds for the development of policy measures to integrate ethnically diverse societies.

Most studies in the pertinent literature have highlighted that natives' attitudes toward immigrants are primarily shaped by economic factors such as household income, employment status, and GDP growth rate. This is due to natives' perceptions of immigrants as their competitors in sharing material resources and jobs in the labor market. At this point, the current study asked: "Are the impacts of economic factors on public attitudes toward immigrants contingent upon countries' economic development and experiences on immigration policies?" By addressing this question, the current study intends to reveal whether public attitudes toward immigrants vary across countries depending on their GDPs and immigration policies. To achieve this objective, this study compares four countries including: United States of America with a high GDP and longserving immigration policies; China with a high GDP, but without effective immigration policies; South Africa with a moderate GDP and long-serving immigration policies; and Turkey with a moderate GDP, but without effective immigration policies (Cohen 1997; Fan 2008; Tolay 2014; WorldBank 2015; Zolberg 2006).

Immigration is a dynamic process, meaning that, amounts and sociodemographic characteristics of inmigrants and out-migrants can always change. Based on these changes, natives' perceptions of immigrants can also change. Research on attitudes toward immigrants and immigration, therefore, should always be replenished. Thus, using G@71 Survey-which was conducted in July, 2015-the current study provides up-to-date evidence on factors associated with attitudes toward immigrants and immigration. Based on the relevant literature and theoretical approaches, the current study established following hypotheses to be tested.

H1: In countries with high GDP rates and longserving immigration policies, economic factors (employment status and household income) do not affect public attitudes toward immigrants. 
H2: In countries with high GDP rates but without long-serving immigration policies, economic factors have an impact on public attitudes toward immigrants.

H3: In countries with moderate GDP rates and longserving immigration policies, economic factors do not affect public attitudes toward immigrants.

H4: In countries with a moderate GDP rates but without long-serving immigration policies, economic factors have an impact on public attitudes toward immigrants.

\section{METHODOLOGY}

\section{Data and Sampling}

The current study draws upon data from the Global @dvisor Wave 71 Survey (G@71), which was administered and coordinated by IPSOS Research Company, and conducted between June $19^{\text {th }}$ and July $3^{\text {rd }}$ in 2015. The G@71 Survey aspires to measure public attitudes toward immigration and immigrant population in different countries. The survey instrument was conducted monthly in 24 countries around the world via the IPSOS Online Panel System. The countries reported in this dataset are Argentina, Australia, Belgium, Brazil, Canada, China, France, Great Britain, Germany, Hungary, India, Israel, Italy, Japan, Mexico, Poland, Russia, Saudi Arabia, South Africa, South Korea, Spain, Sweden, Turkey, and United States of America. The surveys were directed towards an international sample of 17,533 adults between 18 and 64 years of ages in the U.S., Israel, and Canada; and 16 and 64 years of ages in all other countries. Approximately 1000 individuals participated in the survey on a country by country basis with the exception of Argentina, Belgium, Hungary, India, Israel, Mexico, Poland, Russia, Saudi Arabia, South Africa, South Korea, Sweden, and Turkey, where each have a sample of approximately 500 adults. Weighting was employed to balance demographics and ensure that the sample's composition reflects that of the adult population according to the most recent census data of each country.

There were several reasons for using the G@71 data as an appropriate source of data analysis. Firstly, G@71 was an international dataset that measures public attitudes in both developing and developed countries, and that provides the opportunity to compare how public attitudes toward immigrants vary depending on countries' socioeconomic conditions. Secondly, G@71 data was one of the most recent surveys measuring public attitudes toward immigrants worldwide. Considering that the immigration is a dynamic process and that the attitudes toward immigrants depends on individuals' perceptions of how many immigrants reside in countries, results of analysis of this dataset would be very valuable in terms of demonstrating the most recent tendencies in public attitudes. Finally, this survey had only single focal point that was to measure public attitudes toward immigration and immigrants. It covered different aspects of the issue, and provided an opportunity to evaluate the issue from a broader perspective. These characteristics increased the reliability for the survey. Thus, G@71 dataset was used as the source of data analysis in the current study.

Variables

\section{Dependent Variable}

Dependent variable of the current study was public attitudes toward immigrants and it was labeled as "Attitudes". The dependent variable was measured by creating an index based upon how much respondents agreed with the following statements: (1) immigration is good for economy of the country; (2) immigrants make country a more interesting place to live in; (3) immigration has placed too much pressure on public services in the country; and (4) immigration is causing my country change in ways that I don't like. Responses for each statement ranged from "strongly agree $=1$ to strongly disagree $=5$ ". Scores for the first and second statement were reverse coded so that higher scores will represent more positive attitudes. The scores of respondents were summed and divided by the number of questions to keep the original scale ranging from 1 to 5.

\section{Independent Variables}

In current study, economic factors including employment status and household income were used as independent variables. Respondents' employment status was a categorical variable ranging from "full time $=1$ " to "retired $=7$ ". Response categories for this variable included full time, part time, self-employed, a student, a soldier, unemployed, and retired. Respondents' employment status was dummy coded as " $0=$ unemployed (students, soldiers, unemployed, and retired individuals)" and " $1=$ employed (full time, part time, or self-employed individuals)". Similar to employment status, household income was an ordinal variable with three categories including low, medium, and high levels of income. 


\section{Control Variables}

The current study also controlled for some potential confounders. Age, as an interval variable, ranged from 16 to 64 . Sex of respondents (male) was treated as a dichotomous variable as " $0=$ female" and " $1=$ male". Finally, education was an ordinal variable with three categories including low, medium, and high levels of education.

\section{Analytic Strategy}

The models for public attitudes toward immigrants were estimated separately for the United States, China, South Africa, and Turkey by using ordinary least square (OLS) regression. For each countries, one model including independent and control variables were established. Each models demonstrated to what extent attitudes toward immigrants in each country were affected by economic factors such as employment status and household income, when respondents' age, sex, and education were held constant. Results of the statistical analysis were interpreted.

\section{RESULTS}

\section{Descriptive Statistics}

Table 1 presents descriptive statistics of variables used in the analysis for each countries. Starting with the dependent variable, in the U.S., the mean number of attitudes toward immigrants was 2.70 with a standard deviation of 1.01 . This suggested that respondents tended to agree that immigrants affected their country in negative way, and they were likely to exhibit relatively negative attitudes toward immigrants. In regard to independent variables, in the U.S., the mean number of household income was 2.28 with a standard deviation of .67, meaning that respondents generally identified their income between medium and high levels in favor of the medium income level. The average score of employment status, on the other hand, was .63 with a standard deviation of .48 , meaning that about 63 percent of respondents identified themselves as employed in labor market. In addition, about 51 percent of respondents living in the U.S. were male while the mean number of respondents' age was 27.67. Finally, mean number of respondents' educational levels was 1.87 with a standard deviation of .82 , meaning that respondents generally identified their levels of education between low education and medium education.

In China, the average score of attitudes toward immigrants was 3.11 with a standard deviation of .56 . This suggested that Chinese individuals were more likely to exhibit positive attitudes toward immigrants than American individuals. Descriptive statistics of independent variables also showed that the mean number of household income was 2.64 with a standard deviation of .54 , meaning that respondents generally identified their income between medium and high levels in favor of the high income level. The mean number of employment status, on the other hand, was .90 with a standard deviation. This suggested that a very high percentage of respondents identified themselves as employed in a job. About 52 percent of Chinese individuals were male while the average age was 21.34. Finally, the average score of educational level was 2.18 with a standard deviation of .38 , meaning that respondents generally identified their levels of education between medium education and high education.

In South Africa, the mean number of attitudes toward immigrants was 2.64 with a standard deviation of .90. This suggested that respondents tended to agree that immigrants affected their country in negative

Table 1: Descriptive Statistics of Variables Used in the Analysis

\begin{tabular}{|c|c|c|c|c|c|c|c|c|c|c|c|c|}
\hline \multirow{2}{*}{ Variable } & \multicolumn{3}{|c|}{ United States } & \multicolumn{3}{|c|}{ China } & \multicolumn{3}{|c|}{ South Africa } & \multicolumn{3}{|c|}{ Turkey } \\
\hline & Mean & S.D. & $\mathbf{N}$ & Mean & S.D. & $\mathbf{N}$ & Mean & S.D. & $\mathbf{N}$ & Mean & S.D. & $\mathbf{N}$ \\
\hline Attitudes & 2.70 & 1.01 & 1004 & 3.11 & .56 & 1000 & 2.64 & .90 & 500 & 1.92 & .76 & 501 \\
\hline $\begin{array}{l}\text { Household } \\
\text { Income }\end{array}$ & 2.28 & .67 & 1004 & 2.69 & .54 & 1000 & 2.63 & .60 & 500 & 2.79 & .44 & 501 \\
\hline $\begin{array}{l}\text { Employment } \\
\text { Status }\end{array}$ & .63 & .48 & 1004 & .90 & .30 & 1000 & .82 & .38 & 500 & .74 & .44 & 501 \\
\hline Age & 27.61 & 13.90 & 1004 & 21.34 & 11.08 & 1000 & 25.11 & 13.25 & 500 & 19.26 & 9.13 & 501 \\
\hline Sex & .51 & .50 & 1004 & .52 & .50 & 1000 & .52 & .50 & 500 & .58 & .49 & 501 \\
\hline Education & 1.87 & .82 & 1004 & 2.18 & .38 & 1000 & 1.75 & .81 & 500 & 2.42 & .85 & 501 \\
\hline
\end{tabular}


way, and similar to the U.S., they were more likely to exhibit relatively negative attitudes toward immigrants. The mean number of household income, on the other hand, was 2.63 with a standard deviation of .60 , meaning that respondents generally identified their income between medium and high levels in favor of the high income level. In addition, the average score of employment status was .82 with a standard deviation of .38. This suggested that a high percentage of respondents-slightly less than Chinese individualsidentified themselves as employed in labor market. About 52 percent of South African individuals were male while the average age was 25.11 . Finally, the mean number of educational level was 1.75 with a standard deviation of .81 , meaning that South African respondents were relatively lower educated.

Finally, in Turkey, the average score of attitudes toward immigrants was 1.92 with a standard deviation of .76. This suggested that Turkish individuals were the group that exhibit the most negative attitudes toward immigrants when compared to other countries. The mean number of household income was 2.79 with a standard deviation of .74, meaning that most Turkish respondents identified themselves having high level of income. In respect to employment status, the mean number was .74 with a standard deviation of .44 , meaning that about 74 percent of individuals identified themselves as employed in the labor market, which was slightly lower than rates in China and South Africa. About 58 percent of Turkish respondents were male while the average age was 19.26. Lastly, the average score of educational level was 2.42 with a standard deviation of .85 , which was pretty higher than that of other countries.

\section{Ordinary Least Squares Results}

Table 2 presents ordinary least squares regression results showing the relationships of household income, employment status, age, sex, and education with public attitudes toward immigrants in the U.S., China, South Africa, and Turkey. For the United States, only age and education were significantly associated with public attitudes toward immigrants. For each one year increase in respondents' ages, their likelihood of developing positive attitude patterns decreased by .026 point, holding other variables constant $(p<.001)$. Supportive of the pertinent literature (Demidova 2014; Hainmueller and Hiscox 2007), on the other hand, for each one point increase in educational levels, respondents' likelihood of developing positive attitudes increased by about .124 point, all else equal $(p<.001)$. Inconsistent with the past literature (Diaz et al. 2011; Esses et al. 2012; Facchini et al. 2009), however, respondents' household income and employment status were not associated with public attitude toward immigrants. Similar to household income and employment status, unsupportive of relevant literature (Facchini et al. 2013; Mayda et al. 2009), respondents' sex was not associated with public attitudes toward immigrants in the United States.

In contrast to United States and supportive of relevant literature (Esses et al. 2012; Facchini et al. 2009), household income was the only variable which

Table 2: OLS Regression Results Indicating Attitudes Toward Immigrants by Countries

\begin{tabular}{|c|c|c|c|c|c|c|c|c|c|c|c|c|}
\hline \multirow{2}{*}{ Variables } & \multicolumn{3}{|c|}{ United States } & \multicolumn{3}{|c|}{ China } & \multicolumn{3}{|c|}{ South Africa } & \multicolumn{3}{|c|}{ Turkey } \\
\hline & B & SE & $\beta$ & B & SE & $\beta$ & B & SE & $\beta$ & B & SE & $\beta$ \\
\hline $\begin{array}{l}\text { Household } \\
\text { Income }\end{array}$ & .040 & .049 & .026 & .088 & .034 & $.085^{\star * *}$ & .104 & .070 & .069 & .239 & .070 & $.159^{* * *}$ \\
\hline $\begin{array}{l}\text { Employment } \\
\text { Status }\end{array}$ & -.066 & .067 & -.031 & -.047 & .061 & -.025 & -.084 & .106 & -.035 & .253 & .076 & $-.168^{* * *}$ \\
\hline Age & -.026 & .002 & $-.351^{* * *}$ & .001 & .002 & -.022 & -.014 & .003 & $-.212^{* * *}$ & .008 & .003 & $.112^{*}$ \\
\hline Sex & -.056 & .061 & -.028 & .042 & .037 & -.037 & -.123 & .081 & -.068 & $\begin{array}{c}- \\
.030 \\
\end{array}$ & .060 & -.022 \\
\hline Education & .124 & .040 & $.101^{* * *}$ & .089 & .048 & .060 & .105 & .052 & $.094^{* *}$ & .035 & .038 & .046 \\
\hline Intercept & & 3.155 & & & 2.776 & & & 2.685 & & & 2.165 & \\
\hline $\mathrm{R}^{2}$ & & .138 & & & .014 & & & .056 & & & .040 & \\
\hline Adjusted $\mathrm{R}^{2}$ & & .134 & & & .009 & & & .046 & & & .030 & \\
\hline $\mathrm{N}$ & & 1004 & & & 1000 & & & 500 & & & 501 & \\
\hline
\end{tabular}

Note: Ordinary least squares regression coefficients followed by robust standard errors and standardized regression coefficients. ${ }^{*} \mathrm{p}<.05,{ }^{* *} \mathrm{p}<.01,{ }^{* \star *} \mathrm{p}<.001$. 
was significantly associated with public attitudes toward immigrants in China. For one point increase in respondents' household income levels, their likelihood of developing positive attitude patterns toward immigrants increased by about .88 point, when other variables held constant $(p<.001)$. However, Chinese respondents' age, sex, employment status, and educational levels had no effect on their attitudes toward immigrants.

Similar to the United States, age and education were found to be significantly associated with public attitudes toward immigrants in South Africa. For each one year increase in respondents' ages, their likelihood of developing positive attitudes toward immigrants decreased by about .014 point, all else equal $(p<.001)$. Besides, supportive of relevant literature (Demidova 2014; Hainmueller and Hiscox 2007), for each one point increase in respondents' educational levels, their likelihood of developing positive attitudes toward immigrants increased by about .105 point, holding other variables constant $(p<.005)$. Inconsistent with the theoretical approaches and studies in relevant literature, however, economic factors such as household income and employment status, and respondents' sexes had not effect on their attitudes toward immigrants.

Finally, supportive of the pertinent literature (Diaz et al. 2011; Esses et al. 2012; Facchini et al. 2009), household income and employment status were found to be significantly associated with public attitudes toward immigrants in Turkey. For each one point increase in respondents' household income levels, their likelihood of exhibiting positive attitudes toward immigrants increased by about .239 point, all else equal $(p<.001)$. Similarly, being employed in labor market increased respondents' tendency to exhibit positive attitudes toward immigrants by about .253 point, holding other variables constant $(p<.001)$. Apart from these, age was also significantly associated with Turkish respondents' attitudes toward immigrants. For each year increase in respondents' ages, their likelihood of developing positive attitudes toward immigrants increased by about .008 point, all else equal $(p<.05)$. Respondents' sexes and educational levels, however, had no effect on Turkish respondents' attitudes toward immigrants.

\section{DISCUSSION}

This study examined public attitudes toward immigrants by comparing its determinants in four different countries including United States, China, South Africa, and Turkey. The first aim of the current study was to reveal possible determinants of individuals' attitudes toward immigrants depending on their socioeconomic and personal characteristics. Secondly, the current study aimed at revealing whether public attitudes toward immigrants vary across countries depending on their GDPs and immigrationpolicy experiences. To achieve this objective, it compared four countries differing by their economic development and effectiveness of their immigration policies. Finally, by using G@71 Survey-which was conducted in July, 2015-the current study intended to provide up-to-date outcomes regarding the attitudes toward immigrants to deal with the dynamic characteristics of the issue. Initially, four hypotheses were established suggesting that the effects of economic interests on attitudes toward immigrants are contingent upon countries' GDP rates and policy experiences. Results of the ordinary least squares regression analysis supported all of the hypotheses established in the current study.

In United States-unsupportive of the individual economic theories and relevant literature-the current study could not find any effects of economic determinants such as household income and employment status on public attitudes toward immigrants. This was consistent with the collective economic approaches and initial predictions of the current study (Paas and Halapuu 2012). According to the report released by the World Bank (2015), the United States was the biggest economy in the world with a GDP of $17,419,000$ million of US dollars. Given that the United States declared its first regulation of immigrants in 1875 and it has always been exposed to mass migration flows, it gained so much experiences on immigration policies up to the present (Zolberg 2006). This suggests that United States, which is regarded as a melting pot-with its long immigration experiences and highly developed economy-could readily integrate the immigrants into its society. Thus, native people generally do not consider immigrants as their potential rivals in the labor market. For this reason, it is not surprising that the economic factors were not associated with public attitudes toward immigrants in the United States.

As was mentioned before, collective economic theories on attitudes toward immigrants suggested that when countries' GDP are higher, attitudes toward immigrants would be more positive (Paas and Halapuu 2012). Unsupportive of collective economic theories 
and relevant literature, however, the current study found that economic factors such as household income were significantly associated with public attitudes toward immigrants in China, which was the second biggest economy in the world in terms of its GDP rates (World Bank 2015). The results regarding Chinese attitudes toward immigrants were consistent with the initial predictions of the current study. In contrast to the United States, although it has attracted so many African immigrants recently, immigration is a new phenomenon for China. Reforms and policies regarding immigration initiated in 1978 in this country. Its first laws, however, were regulated by the 1985 Law of Administration of Entrance and Exit of Foreigners (Fan 2008). Thus, although it has a powerful economic system, the country does not have a long experience of immigration policies to integrate immigrants into its society. For this reason, it is inevitable that the immigration-as a new phenomenon-can pave the way for a competition between natives and immigrants in labor market. This affects natives' attitudes toward immigrants-as their rivals in labor market-in negative way. In other words, even though a country has a powerful economic structure, public attitudes toward immigrants might be shaped by economic concerns due to its unsuccessful immigration policies.

Similar to the results regarding United States, the current study could not find any association between economic factors and public attitudes toward immigrants in South Africa. Although the results were unsupportive of collective economic theories on attitudes toward immigrants and the extant research (Diaz et al. 2011; Paas et al. 2012), they were consistent with the initial predictions of the current study. With its 349,817 millions of US dollars GDP rates, South Africa is considered as a less developed country than the United States and China (World Bank 2015). However, it has experienced too many immigrant flows throughout the history and developed better immigration policies than some developed countries such as China. In $19^{\text {th }}$ century, for instance, foreign mine workers constituted the vast majority of workers in South Africa (Kotze and Hill 1997). In addition, its first major immigration legislation was regulated by the Immigrants Regulation Act in 1913 (Siddique 2004). As a consequence of its long-serving immigration policies, it succeeded to integrate immigrants into the society and prevented potential conflicts between natives and immigrants. For this reason, the results of the current paper suggesting that there was no association between economic factors and attitudes toward immigrants in South Africa was not surprising. This suggests that in countries without a powerful economic structure, public attitudes toward immigrants does not necessarily have to be shaped by economic concerns. Past immigration experiences and effective immigration policies regarding might eliminate natives' negative attitudes resulting from economic concerns.

Finally, supportive of collective and individual economic theories on public attitudes toward immigrants, the current study found that there was a significant association between economic determinants and attitudes toward immigrants in Turkey (Diaz et al. 2011; Esses et al. 2012; Facchini et al. 2009). This result was also consistent with the initial predictions of the current study. Similar to South Africa, with its 799,535 millions of US dollars GDP rates, Turkey is considered as a less developed country compared to United States and China (World Bank 2015). Unlike South Africa, however, it does not have experienced and powerful immigration policies. Although Turkey has always been a transit country between Middle East and Europe throughout the history, it has failed to develop effective immigration policies. Its first major immigration legislation, for example, dates back to 1990s (Kirisci 2000). For this reason, it could not manage immigration flows and failed to integrate immigrants into the rest of its society. Thus, immigrants have generally been considered by native people as their potential rivals in labor market. This paved the way for negative attitudes toward immigrants in Turkey. This suggests that in a less developed country without effective immigration policies, public attitudes toward immigrants are primarily shaped by economic concerns.

Given these findings, the current study has provided a valuable insight to the literature on attitudes toward immigrants by providing a comprehensive picture of how the effects of economic factors such as household income and employment status on public attitudes toward immigrants are contingent upon countries' immigration-policy experiences, which may provide important implications for researchers and policy makers. First of all, given the results of descriptive statistics, it showed that individuals in countries without powerful economic development and effective immigration policies such as Turkey were more likely to exhibit negative attitudes toward immigrants. It also revealed the factors associated with attitudes toward immigrants in each countries. Secondly, contrary to individual economic approaches on the issue, the current study demonstrated that attitudes toward immigrants did not have to be associated with the 
competition in labor market in countries as could be seen in the results regarding the United States and South Africa. It also refuted the hypotheses of collective economic theories suggesting more positive attitudes in higher-GDP countries by indicating that Chinese individuals' attitudes were primarily shaped by their household income, although China is the second biggest economy in the world. Hence, as distinct from assumptions of individual and collective economic theories on the issue, the current study showed that effects of economic concerns on attitudes toward immigrants were contingent upon countries' immigration histories and effectiveness of their immigration policies. Finally, given that the immigration was a dynamic process in which amounts and sociodemographic characteristics of immigrants could always change, the current study provided up-to-date outcomes on attitudes toward immigrants through using a survey conducted in 2015.

Aside from the crucial contributions of the current study to the literature on public attitudes toward immigrants, it is important to note some limitations that mostly stem from deficiencies in the dataset. This study, for instance, lacks certain demographic variables such as race and ethnicity compared to similar studies conducted in other countries. Since the survey used in the current study was conducted in 24 countries that might have tens of different racial groups with different socioeconomic characteristics, race and ethnicity were disregarded in the survey. Secondly, since the Global @dvisor Wave 71 Survey was a self-reported dataset, it might contain several potential sources of biases. For example, individual might have tended to respond to questions in a manner that would be viewed favorably by others, which might cause a validity problem known as social desirability. This bias might interfere with the interpretation of average tendencies as well as individual differences. Respondents might also have a selective memory, meaning that they might not remember their past experiences or might even remember them incorrectly. They might also attempt to portray events they witnessed as more significant than those in reality. Finally, since the survey included a relatively smaller sample size in some countries such as Turkey and South Africa, this might reduce the reliability. Despite these limitations noted above, this study can be very valuable for both policy makers and researchers who are interested in attitudes toward immigrants.

Given the results of this study, further research might develop its findings in several ways. Firstly, future studies should specifically focus on each country included in the analysis of the current study to obtain results that are broader in scope. Conducting studies in larger and more diverse populations in each country would provide an opportunity to show the influence of economic concerns on attitudes toward immigrants. Secondly, since cultural factors might affect public attitudes toward immigrants, future studies should include sociocultural variables and examine whether their effects are contingent upon countries' immigration policies.

\section{REFERENCES}

Becchetti, Leonardo, Fiammetta Rossetti, and Stefano Castriota 2010. "Real Household Income and Attitude toward Immigrants: An Empirical Analysis." The Journal of SocioEconomics 39(1):81-88. http://dx.doi.org/10.1016/j.socec.2009.07.012

Cohen, Robin. 1997. Global Diasporas: An Introduction. London and New York, NY: Routledge. http://dx.doi.org/10.4324/9780203228920

Diaz, Priscila, Delia S. Saenz, and Virginia S. Y. Kwan. 2011 "Economic Dynamics and Changes in Attitudes Toward Undocumented Mexican Immigrants in Arizona." Analyses of Social Issues and Public Policy 11(1):300-313. http://dx.doi.org/10.1111/j.1530-2415.2011.01255.x

Esses, Victoria M., Paula M. Brochu, and Karen R. Dickson. 2012. "Economic Costs, Economic Benefits, and Attitudes Toward Immigrants and Immigration." Analyses of Social Issues and Public Policy 12(1):133-37. http://dx.doi.org/10.1111/j.1530-2415.2011.01269.x

Facchini, Giovanni and Anna Maria Mayda. 2009. "Does the Welfare State Affect Individual Attitudes toward Immigrants? Evidence across Countries." Review of Economics and Statistics 91(2):295-314. http://dx.doi.org/10.1162/rest.91.2.295

Fan, Cindy C. 2008. China on the Move: Migration, the State, and the Household. London and New York, NY: Routledge.

François, Abel and Raul Magni-Berton. 2013. "Individual Gendered Attitudes toward Immigrants. Empirical Evidence from French Surveys." The Social Science Journal 50(3):321-30. http://dx.doi.org/10.1016/j.soscii.2013.02.004

Hainmueller, Jens and Daniel J. Hopkins. 2014. "Public Attitudes Toward Immigration." Annual Review of Political Science 17(1):225-49.

http://dx.doi.org/10.1146/annurev-polisci-102512-194818

Hainmueller, Jens and M.J.Hiscox. 2010. "Attitudes towards Highly Skilled and Low Skilled Immigration." American Political Science Review 104(1):1-24. http://dx.doi.org/10.1017/S0003055409990372

IOM (International Organization for Migration). 2015. "Migrants and Cities: New Partnership to Manage Mobility." Retreived Nov. 21, 2015 (http://publications.iom.int/system/files/wmr2015 en.pdf).

Kirisci, Kemal. 2000. "Disaggregating Turkish Citizenship and Immigration Practices." Middle Eastern Studies 36(3):1-22. http://dx.doi.org/10.1080/00263200008701316

Murray, Kate E. and David M. Marx. 2013. "Attitudes toward Unauthorized Immigrants, Authorized Immigrants, and Refugees." Cultural Diversity and Ethnic Minority Psychology 19(3):332-41. http://dx.doi.org/10.1037/a0030812

Paas, Tiiu and Vivika Halapuu. 2012. "Attitudes towards Immigrants and the Integration of Ethnically Diverse Societies." Eastern Journal of European Studies 3(2):161-76. 
Pardos-Prado, Sergi. 2011. "Framing Attitudes Towards Immigrants in Europe: When Competition Does Not Matter." Journal of Ethnic and Migration Studies 37(7):999-1015. http://dx.doi.org/10.1080/1369183X.2011.572421

Siddique, M. A. B. 2004. "South African Migration Policy: A Critical Review." Economics Discussion / Working Papers 4(17).

Solakoglu, Ozgur and Suheyl Gurbuz. 2015. "Anti-Immigrant Attitudes in a Developing Country: Turkey." Turkish Studies 10(10):771-792.

Tiiu, Paas and Olga Demidova. 2014. "How People Perceive Immigrants 'Role in Their Country's Life: A Comparative Study of Estonia and Russia." Eastern Journal of European Studies 5(2):117-138.
Tolay, Juliette. 2014. "Deconstructing Turkish Public Attitudes towards Refugees: Empowering Rights over Politization and Self-Gratification." USAK Yearbook of Politics and International Relations 6:1-29.

Ward, Colleen and Anne-Marie Masgoret. 2008. "Attitudes toward Immigrants, Immigration, and Multiculturalism in New Zealand: A Social Psychological Analysis." International Migration Review 42(1):227-48. http://dx.doi.org/10.1111/j.1747-7379.2007.00119.x

World Bank. 2015. "World Development Indicators." Retrieved Nov. 25, 2015 (http://databank.worldbank.org/data/download/ GDP.pdf).

Zolberg, Aristide R. 2006. A Nation by Design: Immigration Policy in the Fashioning of America. New York, NY: Sage Publication.

Received on 17-05-2016

Accepted on 03-06-2016

Published on 01-07-2016

DOI: http://dx.doi.org/10.6000/1929-4409.2016.05.13

(C) 2016 Orak and Solakoglu; Licensee Lifescience Global.

This is an open access article licensed under the terms of the Creative Commons Attribution Non-Commercial License (http://creativecommons.org/licenses/by-nc/3.0/) which permits unrestricted, non-commercial use, distribution and reproduction in any medium, provided the work is properly cited. 